\title{
Influence of the track gradient on the contact temperature at the wheel-rail zone for open-pit locomotives
}

\author{
Ambartsum Keropyan ${ }^{1}$, Alla Gerasimova ${ }^{1, *}$, and Kirill Goloshapov ${ }^{1}$. \\ ${ }^{1}$ National University of Science and Technology "MISIS", street the Lenin prospect,4,Moscow,119049, Russia
}

\begin{abstract}
For open-pit locomotives, application of the existing equations for calculation of the temperature for main-line railway transport is inappropriate, since it doesn't take into account the specific conditions of the open-pit mining, such as increased track gradients ( up to 60\%, in another words $60 \mathrm{~m}$ per $1 \mathrm{~km}$ ). Therefore we proposed to calculate the temperature in the contact zone at the wheel-rail interface according to the derived equation, which takes into account the track gradient of the open pit's rail truck. The calculation results, which were made according developed computational technique, show satisfactory repeatability with the experimental results. As the result of theoretical and experimental investigations have been discovered, that the range of the ruling gradient of the transport incline affects on the temperature changes in the wheelrail contact zone and characterized by temperature factor of the rail track gradient $k_{t g r}$. The results of calculations, made according developed method, show satisfactory repeatability with the experimental results. The approximation error of the mining actual operating conditions factor $K_{m c}$ in the range from $25 \%$ to $45 \%$ is less than $5 \%$.
\end{abstract}

\section{Introduction}

One of the criteria for energy processes estimation, ongoing in the contact zone at the wheel-rail system while torque transmission, is a temperature, which also is indicative of stress-related characteristics changes of materials of interacting solids, as consequence, it characterizes their serviceability and durability. Recommended equation for calculation of the temperature in the contact zone at the wheel-rail interface for generalpurpose railways [1,2] after some manipulations can be represented as:

$$
\theta=\frac{0,0576 K_{n e w / w o r n} \cdot f \cdot U_{r s} \cdot \sqrt{a_{1} \cdot V_{m}}}{\lambda(2 a)^{0,5} \cdot A},
$$

where $\theta$ - temperature in the contact zone at the wheel-rail system, ${ }^{\circ} \mathrm{C}$;

$K_{\text {(new/warn) }}$ - contact conditions index, accordingly for the new rail profile (new) and for the warn-in rail profile (worn), J

$K_{\text {new }}=\frac{4}{3} \pi a^{2} b \sigma_{\max }$ - for the new rail profile;

$K_{\text {worn }}=\pi a^{2} m \sigma_{\max }$ - for the worn-in rail profile;

$f$ - coefficient of friction;

$U_{r s}$ - relative slip ratio, $\%$,

$U_{r s}=\left(V_{\text {slip }} / V_{m}\right) \cdot 100$,

$a_{1}$ - thermal diffusivity, $\mathrm{m}^{2} / \mathrm{s}$, for steel $\mathrm{a}_{1}=11,9 \cdot 10^{-6}$,

$\lambda$ - thermal conductivity, $\mathrm{W} /\left(\mathrm{m}^{* \circ} \mathrm{C}\right)$, for steel $\lambda=44,0$

$a$ - half-width (major semiaxle) of the contact zone, $\mathrm{m}$

$b$ - minor semiaxle of the contact zone, $\mathrm{m}$

$m$ - contact zone width ( for worn-in rail profile), $m$
$A$ - contour area of the contact, $\mathrm{m}^{2}$

$V_{m}$ - locomotive's speed of motion, $\mathrm{m} / \mathrm{s}$

$V_{\text {slip }}$ - profile sliding velocity of the locomotive`s wheel tread, $\mathrm{m} / \mathrm{s}$

$\sigma_{\max }$ - maximum bearing pressure at the contact zone, $\mathrm{MPa}$

Purpose of the work is to investigate the influence of the ruling gradient of the industrial railway on the temperature in the contact zone at the wheel-rail interface.

\section{Objects and methods of research}

For open-pit locomotives, the application of Eq. (1) is inappropriate as it does not take into account the openpit's special conditions- increased track grades, up to $60 \%$. That is why we propose to calculate the temperature in the contact zone at the wheel-rail interface according the further formula:

$$
\theta=\frac{0,0576 K_{n e w / \text { worn }} \cdot K_{m c} \cdot U_{r s} \cdot \sqrt{a_{1} \cdot V_{m}}}{\lambda(2 a)^{0,5} \cdot A},
$$

where $K_{m c}$ - factor, which takes into account mining actual operating conditions.

The nominal dimensions of the contact area can be calculated by Hertz-Belyayev equation $[3,4]$, however, while calculating were used more accurate data, obtained experimentally during working period [2].

The mining actual operating conditions factor $K_{m c}$ can be defined as:

$$
K_{m c}=\left(1+k_{\text {tgr }} \cdot i\right)
$$

\footnotetext{
Corresponding author: allochka@rambler.ru
} 
where $k_{t g r}$ - temperature coefficient, which depends on the track gradient,

$i$ - inclination of the track gradient, \%o

Taking into account Eq. (3), we deduce:

$$
\theta=\frac{0,0576 K_{n e w / w o r n} \cdot f \cdot\left(1+k_{t g r} \cdot i\right) U_{r s} \cdot \sqrt{a_{1} \cdot V_{m}}}{\lambda(2 a)^{0,5} \cdot A}
$$

Investigations, presented in the scientific work [2], were made under the conditions of general-purpose railway tracks, for $80 \%$ of them maximum incline of track gradient is not more than 9\%o [5]. That is why, for track gradients less than $10 \%$ we apply the temperature factor of the rail track gradient $k_{\text {tgr }}=0$. For such operating conditions $K_{m c}=1$ and the temperature can be calculated using the following Eq. (1).

Dependence of coefficient $k_{\text {tgr }}$ on the process variables of wheel-rail interaction can be obtained from the Eq. (4)

$$
k_{t g r}=\frac{\theta \cdot \lambda \cdot(2 a)^{0,5} \cdot A-U_{r s} \cdot 0,0576 \cdot K \cdot f \cdot \sqrt{a_{1} \cdot V_{m}}}{0,0576 \cdot U_{r s} \cdot K \cdot i \cdot f \cdot \sqrt{a_{1} \cdot V_{m}}}
$$

Experimental researches into the determination of $k_{t g r}$ values were carried out on the tunnel locomotive "SCHÖMA-350" (Germany), on the base of JSK"Mosmetrostroy" company, in conditions of under construction subway stations. Were measured temperatures and slip velocities in the contact area at the wheel-rail system for different motion speeds and with different rail track gradients Fig.1. The temperature measurements were carried out by infrared temperature measuring instrument "testo 845" (thermovisor), sliding by the procedure, contained in the engineering manual [6].

Temperature and sliding velocity measuring device for taking measurements in the contact zone at the wheelrail system shown in figure 1 .

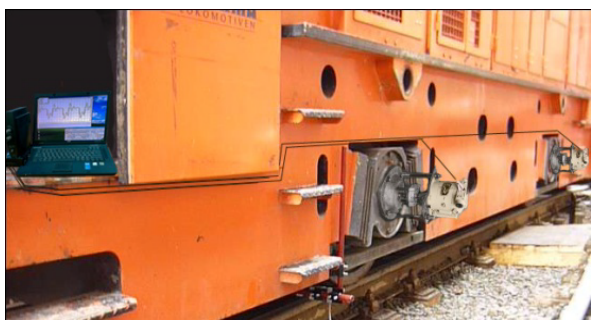

a)

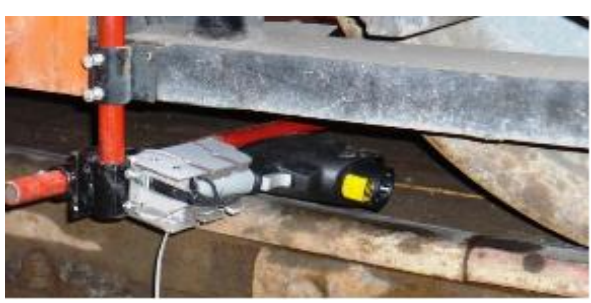

b)

Fig.1. Temperature and sliding velocity measuring device for taking measurements in the contact zone at the wheel-rail system: a) general view; b) unit of an infrared thermometer "testo $845 "$ ".
The measured results are shown in Table 1.

Table 1. Experimental values of sliding velocity and temperature in the contact zone at the wheel-rail system for tunnel locomotive "SCHÖMA-350"

\begin{tabular}{|c|c|c|c|}
\hline \multicolumn{2}{|c|}{ Input data } & \multicolumn{2}{c|}{$\begin{array}{c}\text { Measured data } \\
\text { (average values) }\end{array}$} \\
\hline$V_{m, \mathrm{~m}} / \mathrm{s}(\mathrm{km} / \mathrm{h})$ & $i, \% o$ & $U_{r s}, \%$ & $\theta,{ }^{0} \mathrm{C}$ \\
\hline $1,39(5,0)$ & 5,0 & 3,4 & 82,0 \\
\hline $1,39(5,0)$ & 25,0 & 7,8 & 195,0 \\
\hline $1,39(5,0)$ & 45,0 & 12,3 & 330,0 \\
\hline $2,78(10)$ & 5,0 & 5,6 & 191,0 \\
\hline $2,78(10)$ & 25,0 & 13,2 & 465,0 \\
\hline $2,78(10)$ & 45,0 & 17,5 & 650,0 \\
\hline
\end{tabular}

Values of the factors, needed for the formula evaluation (4), are given in Table 2.

Table 2. Values of the factors for calculations of the temperature in the contact zone at the wheel-rail system

\begin{tabular}{|l|l|l|l|l|l|l|}
\hline $\begin{array}{l}\mathrm{P}, \mathrm{k} \\
\mathrm{N}\end{array}$ & $\begin{array}{l}\text { Kind } \\
\text { of the } \\
\text { rail } \\
\text { profile }\end{array}$ & $\begin{array}{l}a \cdot \\
10^{-3}, \\
\mathrm{~m}\end{array}$ & $\begin{array}{l}\mathrm{A} \cdot \\
10^{-4}, \\
\mathrm{~m}^{2}\end{array}$ & $\mathrm{~K}, \mathrm{~J}$ & $\begin{array}{l}a_{I,} \\
\mathrm{~m}^{2} / \mathrm{s}\end{array}$ & $\begin{array}{l}\lambda, \\
\mathrm{W} /\left(\mathrm{M} \cdot{ }^{0} \mathrm{C}\right)\end{array}$ \\
\hline 175 & $\begin{array}{l}\text { Worn- } \\
\text { in }\end{array}$ & 3,30 & 2,65 & 605 & $\begin{array}{l}11,9 \\
10^{-6}\end{array}$ & 44,0 \\
\hline
\end{tabular}

Equation (4) allows to take into account the influence quantity of several factors on the temperature $\theta$ in the contact zone at the wheel-rail system, such as contour area of contact $A$, axle loading $P$, resultant sliding velocity $U_{r s}$, friction coefficient $f$, locomotive speed $V_{m}$ and value of rail track gradient $i$. The results of the experimental data treatment are shown in Table 3.

From the physical point of view, $\mathrm{K}_{\text {(new/worn) }}$ is an amount of energy, which releases in the contact zone at the wheelrail system, where friction coefficient is $f=1$ and resultant sliding velocity is $\mathrm{U}_{\mathrm{rs}}=100 \%$. On the assumption, that coefficient index $\mathrm{K}_{\text {(new/worn) }}$ can be used in an impact analysis of different parameters (which are determining conditions of wheel-rail interengagement; on the amount of energy, released in-between coworking surfaces while traction mode motion [2]

Hereafter: $\mathrm{K}_{(\text {new/worn) }}=\mathrm{K}_{\text {worn }}=\mathrm{K}$.

Table 3. Calculated values of coefficients $k_{\operatorname{tgr}}$ and $K_{m c}$ according to experimental data

\begin{tabular}{|c|c|c|c|c|c|}
\hline \multicolumn{2}{|l|}{ Input data } & \multicolumn{2}{|c|}{$\begin{array}{c}\text { Experimental } \\
\text { data }\end{array}$} & \multicolumn{2}{l|}{$\begin{array}{l}\text { Data processing } \\
\text { result }\end{array}$} \\
\hline $\begin{array}{l}V_{m} \\
\mathrm{~m} / \mathrm{s}(\mathrm{km} / \mathrm{h})\end{array}$ & $i, \% o$ & $\begin{array}{c}U_{r s}, \\
\%\end{array}$ & $\theta,{ }^{0} \mathrm{C}$ & $k_{t g r} \cdot 10^{-3}$ & $\begin{array}{c}K_{m \mathrm{c}}=1+ \\
k_{y} \cdot i\end{array}$ \\
\hline $1,39(5,0)$ & 5,0 & 3,4 & 82,0 & $\approx 0(0,05)$ & 1,0 \\
\hline $1,39(5,0)$ & 25,0 & 7,8 & 195,0 & 1,5 & 1,0375 \\
\hline $1,39(5,0)$ & 45,0 & 12,3 & 330,0 & 2,5 & 1,1125 \\
\hline $2,78(10)$ & 5,0 & 5,6 & 191,0 & $\approx 0(0,1)$ & 1,0 \\
\hline $2,78(10)$ & 25,0 & 13,2 & 465,0 & 1,33 & 1,0333 \\
\hline $2,78(10)$ & 45,0 & 17,5 & 650,0 & 2,13 & 1,0959 \\
\hline
\end{tabular}


In the work [2] are given values of $\mathrm{K}$ depending on axle loading $\mathrm{P}$, on size of the contact contour area $A$ and on the level of worn-in for conjugated surfaces at the wheel-rail system. It is also shown, that increase of the axle load is accompanied by the increase of coefficient $\mathrm{K}$ and, in the same time, by increasing of released energy at the contact zone. However, with increasing of the contact area, the specific value of released at the wheel-rail contact zone energy is substantially reducing. Accordingly, it may be affirmed, that the worn-in rail profiles (i.e. profiles, which ensure conformal contact) has notably less amount of released heat in the contact zone than the new.

By analyzing Equation (4) it is very easy to note, that with decreasing of the contact conditions coefficient $\mathrm{K}$; of resultant sliding velocity $U_{r s}$; of the friction coefficient $f$ and with increasing of the contacting area of two associated surfaces $A$, the temperature in the contact zone $\theta$ should decrease, and will be increasing with increase of the track gradient.

Received (with account for data, shown in Table 3) dependence of the temperature coefficient $k_{t g r}$ on the track gradient is shown in Figure 2.

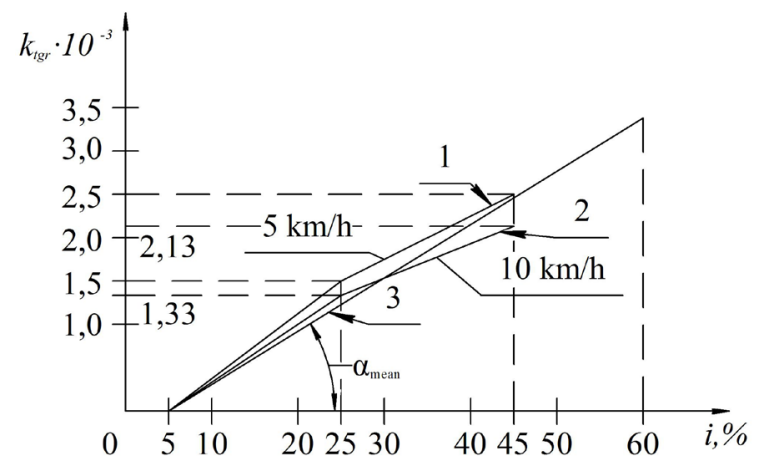

Fig.2. Change of the temperature coefficient $k_{\operatorname{tg} r}$ with inclination of the track gradient : 1,2- experimental curves; 3- approximating curve.

According to Figure 2 can be obtained approximation function $k_{t g r}$ :

$$
K_{\text {tgr }}=(i-5) \cdot \operatorname{tg} a_{\text {mean }},
$$

where $\alpha_{\text {mean }}$-the mean value of gradient angle of approximation curve of the temperature coefficient $\mathrm{k}_{\mathrm{tgr}}$, determined by least square method.

Substituting this value in Eq.(3) we obtain:

$$
K_{m c}=\left[1+(i-5) \cdot \operatorname{tg} a_{\text {mean }} \cdot i\right],
$$

On rearrangement, this result can be written as:

$$
K_{m c}=1+i^{2} \cdot \operatorname{tg} a_{\text {mean }}-5 \cdot i \cdot \operatorname{tg} a_{\text {mean }}
$$

Taking into account the results, obtained after processing of the experimental dataset, we can define $\operatorname{tg} \alpha_{\text {mean }}$ :

$$
\operatorname{tg} \alpha_{\text {mean }}=6,3 \cdot 10^{-5} ; \quad \alpha_{\text {mean }}=0,0036^{\circ} .
$$

$$
K_{m c}=1+6,5 \cdot 10^{-5} \cdot i^{2}-3,15 \cdot 10^{-4} \cdot i
$$

Figure 3 shows dependence diagrams of coefficient $\mathrm{K}_{\mathrm{mc}}$ from the rate of rail track gradient.

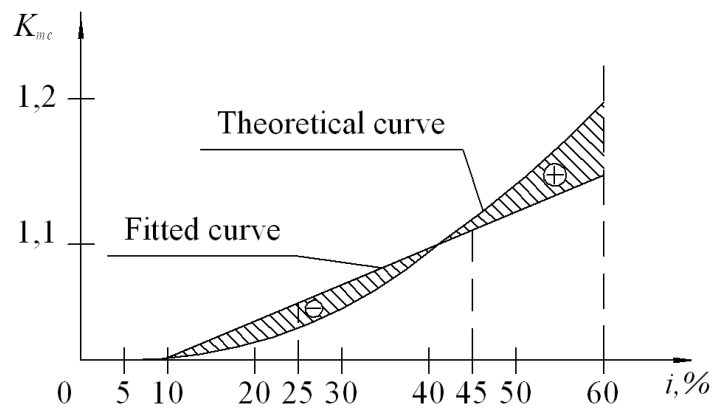

Fig.3. Dependences of theoretical and curve-fitted constants of mining conditions influence $K_{m c}$ on inclination of the rail track gradient.

\section{Results and discussions}

Analysis of experimental results (presented in Table 3), at bound temperature of $300^{\circ} \mathrm{C}$ [7], shows, that the difference under a substitution of a cuspidal function with a linear one is a $\Delta K_{m \mathrm{c}}=0,05$, while the error is not more than $15^{\circ} \mathrm{C}$ or $15 \%$.

In the Table 4 shown values of theoretical (calculated) and curve-fitted constants $K_{m c}$ and given error of approximation $\Delta$.

Table 4. Values of theoretical and curve-fitted constants $K_{m c}$.

\begin{tabular}{|l|l|l|l|l|l|}
\hline$i, \% o$ & 5 & 10 & 25 & 45 & 60 \\
\hline$K_{\text {mc.th. }}$ & 1,0 & 1,00315 & 1,0315 & 1,1134 & 1,2079 \\
\hline$K_{\text {m.app. }}$ & - & 1,0 & 1,048 & 1,106 & 1,15 \\
\hline$\Delta, \%$ & & $-0,315$ & $+1,6$ & $-0,66$ & $-4,79$ \\
\hline
\end{tabular}

In the scientific researches $[8,9]$ have been shown, that under wheel-rail contracting accompanied with high thrust loads (typical for open-pit locomotives) deformations of surface roughness have plastic feature. In this respect, the nominal contact area of interacting surfaces can be defined by Hertz-Belyayev equations [4] and is taken to be equal to the size of the contour contact area [10].

In consideration of the results of complexes of science works, held by several researches $[1,11,12]$, furthermore, taking into account studies of open-pit's railways contamination, given in science works $[13,14]$ and based on criteria that the temperature in the rail-wheel contact must be less then $300^{\circ} \mathrm{C}$, which was determined in the works $[7,15]$. From Eq. 2 can be determined the assumed value of the allowable slip velocity $U_{r s}$ of open-pit locomotives wheels.

Substituting values of Eq.(9) in Eq.(8) we obtain: 


$$
U_{r s}=\frac{\theta \cdot \lambda \cdot(2 a)^{0,5} \cdot A}{0,0576 K \cdot K_{m c} \cdot f \cdot \sqrt{a_{1} \cdot V_{m}}}
$$

The Fig. 4 shows dependences of allowable range of the wheelslip velocity on the rail track gradient at the temperature of $300^{\circ} \mathrm{C}$, at $15 \mathrm{~km} / \mathrm{h}$ and under the axleload of $270 \mathrm{kN}$ for the new and worn-in locomotive's wheel profiles, plotted according to the Eq. (11)

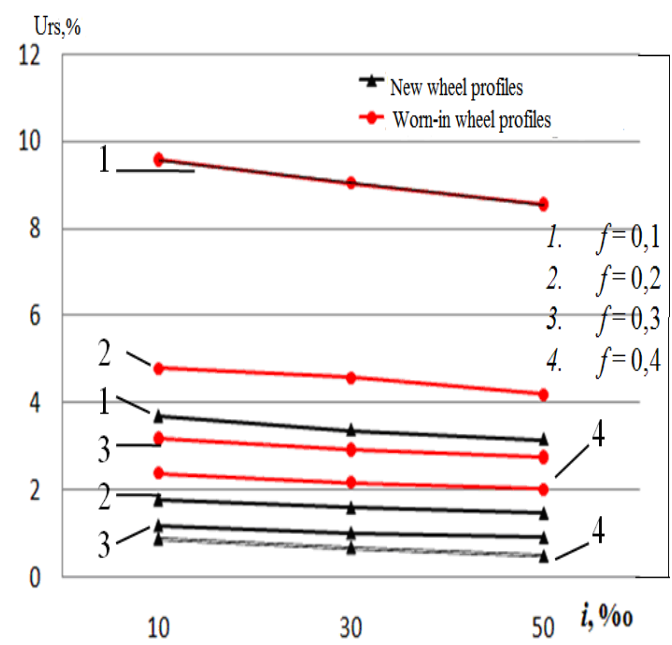

Fig.4. Charts of the allowable range of the wheelslip velocity for new and worn-in wheel profiles at the temperature of $300^{\circ} \mathrm{C}$, at $15 \mathrm{~km} / \mathrm{h}$ and under axleload of $270 \mathrm{kN}$ for the friction coefficient range from 0,1 to 0,4 .

\section{Conclusions}

1. Has been determined that the ruling track gradient value of the transport incline affects on the temperature at the wheel-rail contact zone and is characterized by temperature factor of rail track gradient $k_{t g r}$.

2. Value of the temperature factor of the rail track gradient $k_{\text {tgr }}$ over the range 0 to $10 \%$ is $k_{t g r}=0$, and calculation of the temperature at the wheel-rail system for the open-pit mining conditions should be done according equations recommended for general-purpose railways.

3. With angle increase of the track gradient, the temperature at the wheel -rail system grows up.

4. The results of calculations by the suggested method, show reasonably repeatable results with the experimental. The approximation error of the mining actual operating conditions factor $K_{m c}$ over the range $25 \%$ to $45 \%$ is less then $\pm 5 \%$.

The work was carried out with financial support from the Ministry of Education and Science of the Russian Federation in the framework of increase Competitiveness Program of NUST "MISIS", implemented by a governmental decree dated 16th of March 2013, № 211.

\section{References}

1. A.V. Chichinadze, Calculation and investigation of external friction during braking (Science, Moscow, 1967)
2. K.P. Flyachinskiy, Effect of conditions of interaction of wheels and rail by frictional processes in the contact zone (Ph.D. thesis, Moscow, 1993)

3. S.V. Amelin, Proceedings of LIIZHT, 210 (1963)

4. G.S. Pisarenko, A.P. Yakovlev, V.V. Matveyev, Handbook on strength of materials (Naukova dumka, Kiev, 1975)

5. V.D. Kuz'mich, V.S. Rudnew, S.Y. Frenkel, The theory of locomotive traction (Marshrut Pub, Moscow, 2005)

6. A. M. Keropyan, Yu. E. Babichev. J. Mining equipment and electromechanics, 2, 24 (2015)

7. A. M. Keropyan, K.I. Shakhova. J. Mining equipment and electromechanics, 9, 30 (2013)

8. C. M. Gorbatyuk, et al., J. Metallurgist, 42, 178 (1998)

9. A. A. Gerasimova, A. G. Radyuk, L. M. Glukhov, J. Metallurgist, 58, 397 (2014)

10. N. B. Demkin, Contacting of rough surfaces (Science, Moscow, 1970)

11. M.I. Ruditsyn, Handbook on strength of materials (Higher education, Minsk, 1970)

12. Yu. M. Luzhnov, Nanotribology of wheel-rail adhesioin. Reality and opportunities (Intekst, Moscow, 2009)

13. N.M. Belyaev, Strength of materials (State Publishing House of technical and theoretical literature, Moscow, 1976)

14. A. M. Keropyan, J. Friction and Wear, 1, 78 ( 2016)

15. A. M. Keropyan, S.M. Gorbatyuk, ICIE, 150, 406 (2016) 